\title{
El análisis de las características de los grupos étnicos africanos en el suburbio de Foshan desde la perspectiva de la movilidad
}

\author{
Xin Jin \\ Utrecht University. Department of Geography \\ x.jin1@uu.nl \\ Zhigang Li \\ Sun Yat-sen University. School of Geography and Planning \\ lizhig@mail.sysu.edu.cn
}

Recepción: junio de 2016

Aceptación: enero de 2017

\section{Resumen}

La movilidad se ha convertido en un término popular en el siglo XxI, al mismo tiempo que el análisis de la formación y las características dinámicas de las comunidades étnicas ha ido cobrando una mayor importancia en las investigaciones recientes. En el presente estudio, se lleva a cabo una comparación entre el colectivo de africanos que residen en las ciudades de Guangzhou y Foshan. El trabajo se realiza desde la perspectiva de la movilidad y de sus comportamientos más destacados. En los contextos económico, social y político chinos, los suburbios étnicos han ido adquiriendo un mayor protagonismo, tanto por las pautas de movilidad que en ellos se desarrollan y en las que cobran una relevancia especial el espacio residencial, el tiempo de viaje y el medio de transporte, como por las características de la población inmigrante que en ellos reside, su identidad, las redes sociales que desarrollan, la fijación de sus establecimientos comerciales, etc. Estamos ante lugares cuya naturaleza es dinámica, compleja y está directamente relacionada con la situación de ilegalidad de los inmigrantes. A lo largo de este artículo, el trabajo de campo desarrollado y la aplicación de metodologías cuantitativas y cualitativas permitirán observar cómo, frente a los cambios que se producen en los contextos económico y político, las nuevas prácticas de movilidad de carácter transnacional y transregional de los migrantes pueden provocar la transformación de las comunidades étnicas tradicionales y el surgimiento de nuevos suburbios étnicos.

Palabras clave: suburbios étnicos; movilidad; inmigrantes africanos; Foshan 
Resum. L'anàlisi de les característiques dels grups ètnics africans al suburbi de Foshan des de la perspectiva de mobilitat

La mobilitat s'ha convertit en un terme popular al segle xxI, alhora que l'anàlisi de la formació $\mathrm{i}$ les característiques dinàmiques de les comunitats ètniques ha anat adquirint més importància en les investigacions recents. En el present estudi, portem a terme una comparació entre el colllectiu d'africans que resideixen a les ciutats de Guangzhou i Foshan. L'anàlisi es du a terme des de la perspectiva de la mobilitat i dels seus comportaments més destacats. En els contextos econòmic, social i polític xinès, els suburbis ètnics han anat adquirint més protagonisme, tant per les pautes de mobilitat que s'hi desenvolupen i en les quals cobra una rellevància especial l'espai residencial, el temps de viatge i el mitjà de transport, com per les característiques de la població immigrant que hi viu, les xarxes socials que s'hi desenvolupen, la fixació dels seus establiments comercials, etc. Estem davant de llocs que mostren una naturalesa dinàmica, complexa i directament relacionada amb la situació d'il.legalitat dels immigrants. Al llarg d'aquest article, el treball de camp desenvolupat i l'aplicació de les metodologies quantitatives i qualitatives permetran observar com, enfront dels canvis que es produeixen en el context econòmic i polític, les noves pràctiques de mobilitat de caràcter transnacional i transregional dels migrants poden provocar la transformació de les comunitats ètniques tradicionals i el sorgiment de nous suburbis ètnics.

Paraules clau: barris ètnics; mobilitat; immigrants africans; Foshan

\section{Résumé. L'analyse des caractéristiques des groupes ethniques africains dans la banlieue de Foshan dans la perspective de la mobilité}

Au $21^{\mathrm{e}}$ siècle, le terme mobilité est devenu populaire et l'analyse de la formation et les caractéristiques dynamiques des communautés ethniques revêtent une grande importance dans les recherches récentes. Notre étude fait l'objet d'une comparaison entre le collectif d'Africains qui résident dans les villes de Guangzhou et Foshan. Le travail est fait dans une perspective de la mobilité et de ses comportements les plus remarquables. Du point de vue économique, social et politique chinois, les banlieues ethniques ont joué un rôle de plus en plus important que ce soit par les flux de mobilité qui s'y développent et où l'espace résidentiel, la durée de voyage et le moyen de transport sont primordiaux, que par les caractéristiques de la population immigrante résidente, son identité, les réseaux sociaux qu'ils développent, l'établissement des commerces, etc. Nous nous trouvons face à des lieux qui possèdent une nature dynamique et complexe et qui en rapport direct avec la situation d'illégalité des immigrants. Le travail sur le terrain et l'application de méthodologies quantitatives et qualitatives permettront de faire remarquer que, face aux changements en cours du point de vue économique et politique, les nouvelles expériences de mobilité à caractère transnationale et trans-régionale des migrants peuvent mener à la transformation des communautés ethniques et à l'apparition de nouvelles banlieues ethniques.

Mots-clés: banlieues ethniques; mobilité; immigrants africains; Foshan

\section{Abstract. The rise of the African ethnoburb in Foshan City under the 'mobility turn'}

Mobility has become a popular word and a powerful statement in the 21 st century, while the analysis of the formation and dynamic characteristics of ethnic communities has become increasingly important in recent research. This study compares the group of Africans residing in the ethnic suburbs of Guangzhou and Foshan from the perspective of mobility and their prominent behaviours. In the Chinese economic, social and political context, ethnic suburbs have attracted increasing attention due to both the patterns of 
mobility developed in them, in which residential space, travel time and means of transport are of particular relevance, and the characteristics of the immigrant population living in them, their identity, the social networks they develop and the location of their commercial establishments, among other factors. These are spaces whose dynamic and complex nature is directly related to the illegal status of the immigrants. The fieldwork carried out and the application of quantitative and qualitative methodologies show how, in the face of changes occurring in the economic and political context, the new transnational and trans-regional mobility practices of migrants can transform traditional ethnic communities and favour the emergence of new ethnic suburbs.

Keywords: ethnoburb; mobility; Africans immigrants; Foshan City

\section{Sumario}

$\begin{aligned} \text { 1. Introducción } & \text { 3. El análisis de las características } \\ \text { 2. Caso de estudio, concepto } & \text { 4. Conclusiones étnico en Foshan } \\ \text { y metodología de investigación } & \begin{array}{l}\text { 4. Conclusiones } \\ \text { Referencias bibliográficas }\end{array}\end{aligned}$

\section{Introducción}

Desde la segunda mitad del siglo xx, con el advenimiento de la revolución de las tecnologías de la información y el rápido desarrollo del transporte, la ola de la globalización ha superado las fronteras entre países. En virtud de la nueva división internacional del trabajo, el mundo se está transformando desde un «espacio de la movilidad» hasta un «espacio regional» (Bodomo y Ma, 2010). La sociedad transnacional, económica y cultural formada por las prácticas de los inmigrantes ha generado una nueva actitud en el escenario mundial. Sin embargo, la reestructuración política y económica, la inmigración mundial, los cambios de la política comercial y la transformación en aspectos como la población, la economía y la política de cada ciudad, etc. están remodelando constantemente las prácticas transversales de los migrantes internacionales. Además, los mismos promueven la revolución demográfica, económica, política y espacial de las ciudades de destino (Guangtian, 2005; Bodorno y Ma, 2012). Con el avance del proceso de metropolitanización en China, el fenómeno étnico comienza a aparecer cada vez más en los suburbios.

Conocida como "la fábrica del mundo», la región del delta del río Perla y sus productos de fabricación barata han atraído a los inmigrantes de los países africanos. Guangzhou, como centro de la región del delta del río Perla, ha sido, desde la antigüedad, una urbe más abierta y, por consiguiente, más inclusiva que Beijing, Shanghai y otras metrópolis. En la actualidad, se ha convertido en una "ciudad de asentamiento" (Castells, 2000) para los inmigrantes que provienen de algunos de los países menos desarrollados de África. De esta manera, progresivamente, se han ido formando en ella diferentes enclaves étni- 
cos africanos, como los de San Yuan Li, Xiao Bei, etc., que han sido objeto de numerosos estudios (Wei, 2006; Wissink et al., 2012; Wu y Webber, 2004; Xiaoyan, 2011; Ye, 2012; Zhou y Lin, 2004; Zhou, 1998). Cabe destacar las investigaciones llevadas a cabo por Lyons et al. (2008, 2012, 2013), quienes consideran que las redes sociales de los comerciantes africanos en Guangzhou componen el «tercer nivel» de la globalización, por detrás de las organizaciones mundiales y los países (Chen, 2012). Asimismo, Connell e Ip (1981) y Zhang (2008) se han referido al paradigma de la relación global y local con el fin de discutir la formación y el desarrollo de las comunidades étnicas en Guangzhou. Por su parte, investigadores como Zhigang, en colaboración con Desheng y otros autores (Zhigang et al., 2008, 2009; Zhigang y Feng, 2012a, 2012b), o Liu et al. (2010), han llevado a cabo diversas colaboraciones con el fin de caracterizar diferentes barrios de población de origen africano de Xiaobei, así como explorar el impacto local derivado de la aparición de estos nuevos espacios sociales en las ciudades chinas en el contexto de la globalización (Sun, 2012). Las comunidades étnicas africanas en Guangzhou se describen como un nuevo tipo de espacio emblemático transnacional y se consideran como un «fenómeno temporal de la globalización» (Han, 2013; Smith, 2001). Por su parte, Haugen (2012) ha estudiado el impacto local de la movilidad de los migrantes, que vienen de "otro estado con un tipo de movilidad forzada" (Hannam et al., 2006), al mismo tiempo que otros estudios (Harvey, 1989; Haugen, 2012; Hebo, 2008; Kim, 2003; Kwong, 1987; Soja, 1989; Zhigang et al., 2009) focalizan su interés en aspectos vinculados con la economía, la cultura, la lengua, la gastronomía, etc. En líneas generales, puede afirmarse que estos trabajos se han centrado principalmente en el análisis de los flujos de movilidad de los inmigrantes traídos por las prácticas transnacionales, en cambio, son muy escasas las investigaciones que tratan sobre el impacto que han generado dichas prácticas transnacionales en el ámbito local, por lo que el conocimiento referido al desarrollo y a la evolución de las comunidades étnicas es limitado. Sobre esta premisa, en el presente estudio, se ha delimitado el área de Huangqi en Foshan como ejemplo de este tipo de enclaves étnicos, para llevar a cabo un examen pormenorizado de sus características, no solo con el objetivo de responder a las cuestiones que plantea el paradigma de investigación de la movilidad, sino también para cubrir ciertos vacíos de análisis relacionados con el tema.

\section{Caso de estudio, concepto y metodología de investigación}

\subsection{Huangqi, Foshan}

En este estudio, se han definido los suburbios étnicos africanos en Foshan como aquellos espacios de reunión de población de origen africana que se detectan en el área de Huangqi (Foshan). Huangqi se encuentra al este del distrito de Nanhai, que forma parte de la ciudad de Foshan y está próxima a Guangzhou. Esta área se conoce como el «corredor de oro de Guangfo» 

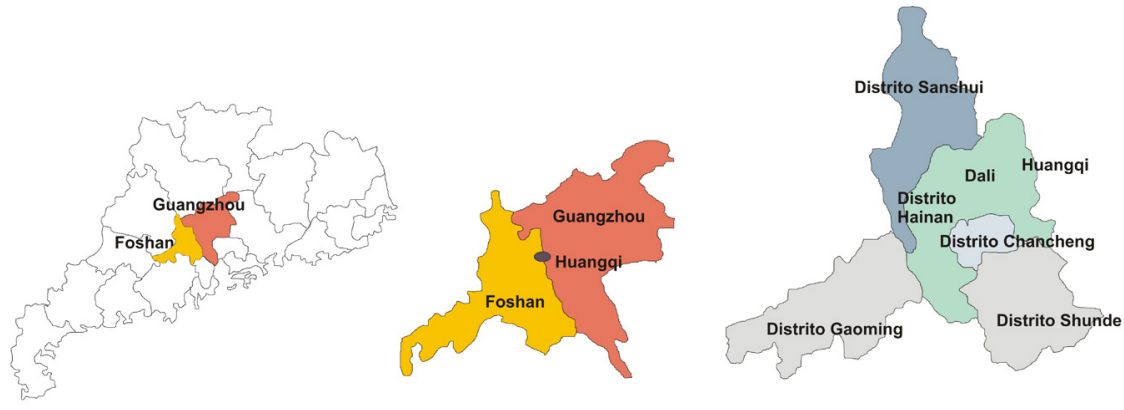

Fuente: elaboración propia.

(figura 1). La superficie total de las calles de Huangqi es de 19,84 kilómetros cuadrados. Su población permanente es de 50.000 individuos, aunque el total de habitantes alcanza las 130.000 personas aproximadamente.

La selección de este caso de estudio se ha basado en dos motivos. En primer lugar, mucha gente se ha establecido en las calles de Huangqi, que se han visto beneficiadas por el proceso de suburbanización. Desde el inicio de la década de 1990, el crecimiento de la ciudad de Guangzhou comenzó a desbordar las divisiones administrativas y se extendió por las zonas que rodeaban a la ciudad tradicional. La industria y el comercio al por mayor se fueron instalando gradualmente desde la ciudad a lo largo de la carretera Guangzhou-Foshan Nanhai, un hecho que favoreció que muchos ciudadanos que vivían cerca de la ciudad de Guangzhou empezaran a establecerse en esta nueva zona. Fue así como dio comienzo el desarrollo inmobiliario de Huangqi y se formó finalmente el eje denominado «avenida Zhongshanjiu». Después de diez años de crecimiento, una gran cantidad de personas en Guangzhou viven en un área de menos de 20 kilómetros cuadrados correspondiente a Huangqi.

En segundo lugar, los comercios, la industria de servicios y otras actividades también se han integrado en la ciudad. Desde que comenzó la estrategia de «la integración de Guangzhou y Foshan», la avenida Zhongshanjiu se convirtió en un ejemplo de dicha integración. En la actualidad, se conoce como el "corredor de oro de comercio de Guangfo", y es un modelo ejemplar de vía comercial. La estrategia de integración de las ciudades de Guangzhou y Foshan ha consistido en la creación de más transporte público, por ejemplo: la línea 5 del metro y la línea Guangfo. Además, se han establecido diversos servicios regulares de autobuses, que han permitido vincular estrechamente Guangzhou con Huangqi. Por eso, aunque Huangqi no pertenece a Guangzhou administrativamente, desde la perspectiva de la ciudad gigante se ha convertido en un barrio extremadamente importante para Guangzhou en su proceso de desarrollo. Dicha proximidad y la buena conexión entre ambas ha favorecido la llegada a Huangqi de un número importante de inmigrantes de África dedicados al 
comercio, que hacen negocios en Guangzhou y que han fijado su residencia en esta área de expansión de la ciudad. La concentración de estos comerciantes africanos se refleja en el carácter multiétnico y multicultural de dicha área.

\subsection{El concepto de suburbio étnico ${ }^{1}$}

El suburbio étnico (ethnoburb) (Zhigang et al, 2009) es también un suburbio multiétnico (multiethnic suburb) y un nuevo tipo de residencia de un grupo étnico. El «suburbio de etnias diversas» es una expresión espacial referida a las relaciones específicas de cada grupo étnico. Su forma espacial y su estructura socioeconómica interna diversa es el resultado de las diferencias y de las relaciones entre los grupos y los estratos étnicos. El suburbio étnico se encuentra dentro del ámbito de influencia de las grandes ciudades, aunque se localiza en las afueras de las mismas, dispone de distrito residencial y de negocios y es una comunidad multirracial y multicultural. En el suburbio étnico, los grupos minoritarios tienden a agruparse, aunque no son los que más destacan dentro del mismo. Funciona como un tipo de espacio residencial, que comparte características con los enclaves étnicos y los suburbios, pero al que le falta una identidad común entre los grupos de distintas minorías étnicas (Chen, 2012; Fang y Liang, 2010; Sun, 2009). En los últimos años, dada la proliferación de diferentes asentamientos étnicos urbanos y suburbanos, los suburbios étnicos se han convertido en una nueva forma residencial contemporánea en la que coexisten nuevos grupos étnicos (tabla 1) y que se diferencia del tugurio y de los enclaves étnicos tradicionales. Desde el punto de vista de la investigación, se ha prestado atención a los cambios que ha supuesto su auge, a las diferencias entre los mismos y los suburbios de los países occidentales, a su mecanismo de formación, a su existencia en la ciudad contemporánea y a las disparidades existentes entre los suburbios étnicos, el tugurio y los enclaves étnicos tradicionales.

Son diversos los factores que afectan a la formación y al desarrollo de estos suburbios. En general, se diferencian los factores externos de los internos. Los primeros incluyen la restauración de la economía mundial, la dualización de la economía étnica, las condiciones de los países de origen de los inmigrantes y las políticas nacionales y locales, etc. Por otro lado, los factores internos se refieren a los conflictos entre partidos políticos, a la lucha común o de grupo, a las movilizaciones y a los cambios sociales, que afectan a la formación y a la transformación de las comunidades étnicas. El proceso dinámico global, nacional y local ha afectado a la inmigración desde perspectivas diferentes. Se ha transformado la población de los suburbios, las características socioeconómicas locales y las estructuras económicas y políticas, con lo que se han reconstruido los paisajes residenciales y comerciales.

1. En el texto original en inglés, se utilizan los conceptos de ghetto, ethnic enclave y ethnoburb, que aquí se han traducido como tugurio, enclave étnico tradicional y suburbio étnico. (N. de los e.) 
Tabla 1. Comparación entre las características del suburbio étnico frente al tugurio y el enclave étnico tradicional

\begin{tabular}{|c|c|c|c|c|c|}
\hline & Localización & $\begin{array}{l}\text { Dinámica } \\
\text { de formación }\end{array}$ & $\begin{array}{l}\text { Característica } \\
\text { económica }\end{array}$ & $\begin{array}{l}\text { Características } \\
\text { de grupos étnicos }\end{array}$ & $\begin{array}{l}\text { Características } \\
\text { residenciales }\end{array}$ \\
\hline Tugurio & $\begin{array}{l}\text { Centro de } \\
\text { la Ciudad. }\end{array}$ & $\begin{array}{l}\text { Discriminación } \\
\text { étnica. }\end{array}$ & $\begin{array}{l}\text { Deterioro } \\
\text { económico. }\end{array}$ & $\begin{array}{l}\text { Compuestos } \\
\text { principalmente } \\
\text { por grupos étnicos. } \\
\text { Capacidad } \\
\text { económica débil. }\end{array}$ & $\begin{array}{l}\text { Viven aisladamente } \\
\text { con los grupos dominantes. } \\
\text { Los grupos étnicos viven } \\
\text { juntos. }\end{array}$ \\
\hline $\begin{array}{l}\text { Enclave étnico } \\
\text { tradicional }\end{array}$ & $\begin{array}{l}\text { Centro de } \\
\text { la Ciudad. }\end{array}$ & $\begin{array}{l}\text { Discriminación } \\
\text { étnica. }\end{array}$ & $\begin{array}{l}\text { Economía étnica } \\
\text { desarrollada. }\end{array}$ & $\begin{array}{l}\text { Compuesto } \\
\text { principalmente } \\
\text { por grupos étnicos. } \\
\text { Capacidad } \\
\text { económica débil. }\end{array}$ & $\begin{array}{l}\text { Viven aisladamente con } \\
\text { los grupos dominantes. } \\
\text { Los grupos étnicos viven } \\
\text { juntos. }\end{array}$ \\
\hline Suburbio étnico & $\begin{array}{l}\text { Periferia de } \\
\text { la ciudad. }\end{array}$ & $\begin{array}{l}\text { Posición } \\
\text { económica } \\
\text { elevada. }\end{array}$ & $\begin{array}{l}\text { Economía étnica } \\
\text { desarrollada. }\end{array}$ & $\begin{array}{l}\text { Grupos étnicos } \\
\text { escasa } \\
\text { representatividad. } \\
\text { Fuerte capacidad } \\
\text { económica. }\end{array}$ & $\begin{array}{l}\text { Viven con grupos } \\
\text { dominantes. Los grupos } \\
\text { étnicos viven de forma } \\
\text { dispersa. }\end{array}$ \\
\hline
\end{tabular}

Fuente: Li (2006).

\subsection{Concepto de movilidad}

Con la movilidad del capital, el trabajo y la tecnología a lo largo de todo el mundo, se ha favorecido la creación de una economía y de una forma de vida social en red. La movilidad se ha convertido en un término popular y en una expresión poderosa en el siglo xxI, y ha ejercido un gran impacto en el ámbito académico (Urry, 2000; Zhigang y Feng, 2012a, 2012b). Entre las investigaciones llevadas a cabo, destacan aquellas referidas a la movilidad masiva de personas, objetos, capital e información del mundo, así como el proceso del movimiento de tráfico diario local en el espacio público y derivado de la vida cotidiana (Zhigang et al., 2009). Este paradigma de investigación ha transformado la metodología tradicional de investigación en las ciencias sociales, la del «lugar» y la de «lo estático», y ha cambiado la noción que consideraba al lugar y a la residencia como elementos estables por naturaleza, al entenderlos como una condición común de la movilidad de la posmodernidad y la globalización, más allá del pensamiento vinculado a lo "zonal», que se ve como un contenedor geográfico fijo del proceso social (Zhigang y Feng, 2012a, 2012b). El análisis sobre la solución espacial y la reconstrucción del espacio es uno de los campos más importantes en la investigación de la movilidad geográfica (Yungang y Yuwen, 2010; Yungang et al., 2010). La movilidad se analiza en relación con el espacio en el cual se desarrolla, la estructura básica y el sistema, es decir, lo que se conoce como «solución espacial» (spatial fix) (Yungang et al., 2010; Harvey, 2003). Después de la década de 1990, en el contexto neoliberal de la globalización, la movilidad ha dado un nuevo significado a la geografía y al espacio. La producción de geoespacio se ha visto afectada por los impactos 
globales y locales y se ha convertido en un proceso de «relocalización», en lugar de «trasladar la localización» a diferentes escalas. El mundo, los países y las ciudades también han sufrido el impacto de estas movilidades que cambian constantemente (Zhigang y Feng, 2012a, 2012b).

En consecuencia, el proceso de la formación global y local de los suburbios étnicos puede interpretarse a partir de la perspectiva de la movilidad, explorando los nuevos espacios urbanos construidos a raíz de los cambios en los comportamientos de los inmigrantes. Debe considerarse que la movilidad de la migración transnacional no solo es una consecuencia de la globalización, sino que también está influida por el ambiente político y económico en el lugar de origen. Por otra parte, la globalización de la cultura económica mundial, la reconstrucción del sistema global, la transformación urbana de China y sus relaciones exteriores, la política de inmigración china, etc. conforman una serie de factores íntimamente relacionados que favorecen dicha movilidad. Es por ello que el presente estudio va a indagar en aspectos como ¿QQué sistema de movilidad se construye a raíz de los flujos migratorios transnacionales? ¿Qué efecto tiene este sistema de movilidad en el espacio urbano y a qué tipo de espacio étnico da lugar?

Figura 2. Lugar de residencia de los encuestados
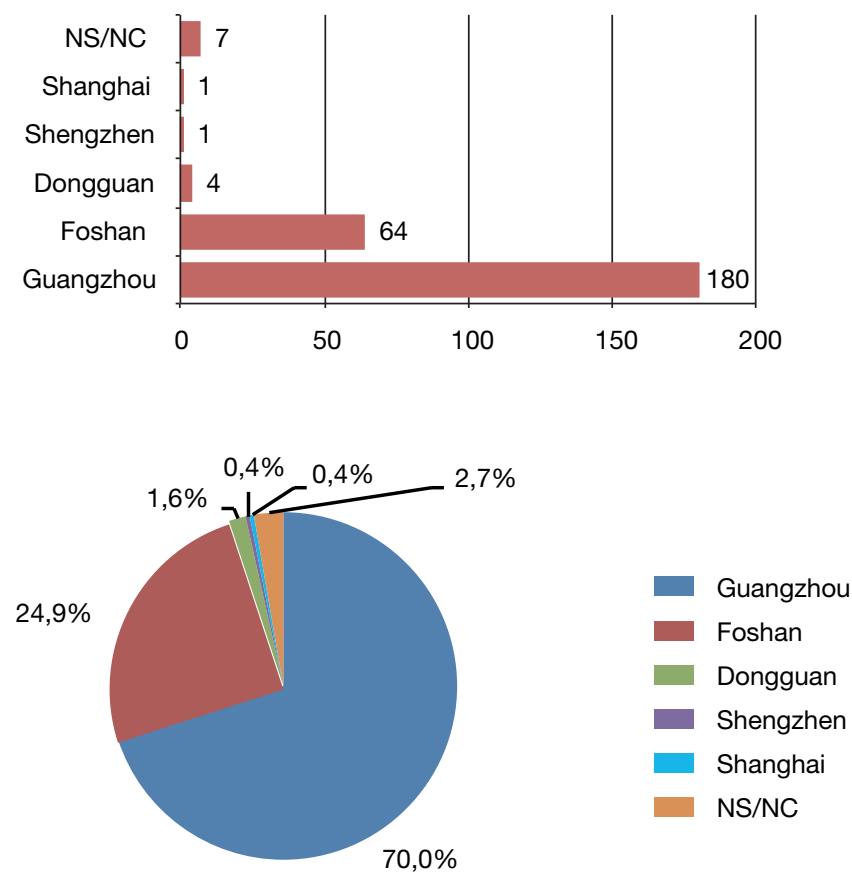

Fuente: elaboración propia a partir de encuesta. 


\subsection{Metodología de investigación}

Esta investigación utiliza las metodologías cuantitativa y cualitativa. Por una parte, se realizó una encuesta en 2010 a los africanos en Guangzhou y Foshan, de la cual se obtuvieron 257 entrevistas. 64 de las personas con quienes se mantuvieron las conversaciones viven en Foshan; 180, en Guangzhou, y los 13 restantes, en otras ciudades (figura 2). Además, se desarrolló un trabajo de campo durante seis meses, entre octubre de 2013 y marzo de 2014, en Guangzhou y Foshan, que incluyó la realización de entrevistas semiestructuradas, observación participante, etc. Las notas de campo y las conversaciones grabadas han sido las fuentes básicas para realizar el análisis cualitativo. A la hora de seleccionar a los entrevistados, se intentó elegir a africanos con tiempo de estancia, capacidad económica, situación familiar, etc. diferentes. La muestra que se ha conseguido es de 30 africanos y 12 chinos. Entre estos últimos, se encuentran cónyuges de africanos, administradores del distrito, propietarios de tiendas, dueños de restaurantes, propietarios de apartamentos, comerciantes exteriores de China y empresarios extranjeros que trabajan en la oficina de policía y el centro de gestión de servicios para los extranjeros, etc. Finalmente, se han supervisado las diferentes investigaciones y políticas existentes sobre inmigrantes africanos de China.

\section{El análisis de las características del suburbio étnico en Foshan}

\subsection{Características básicas}

Según el cuestionario de 2010, se constata que, en general, los africanos que viven en el área de Huangqi de Foshan manifiestan grandes similitudes. Debido a la escasa población femenina africana en este territorio, en Foshan solo se dispone de encuestados masculinos. La mayoría procede de Nigeria y supone un $84,4 \%$ de todas las entrevistas. La edad predominante es la joven y adulta (de 18 a 39 años), que representa un $89 \%$ del total de esas entrevistas. En cuanto al nivel educativo, el universitario representa un $28,1 \%$; el de bachillerato, un 26,6\%, y el de educación secundaria, un 37,5\%. Por lo que respecta al estado civil, los solteros son un $64 \%$; los casados, un $2 \%$, y un $11 \%$ más tiene pareja fija. Asimismo, en términos religiosos, casi todos son cristianos $(97,3 \%)$. Finalmente, si se tiene en cuenta el tipo de visado, se observa que un $81,3 \%$ de los entrevistados entró en China con el de negocios y un 12,5\%, con el de turista (tabla 2).

A través del análisis comparativo de las personas entrevistadas que viven en Guangzhou y en Foshan, se podrán extraer algunas de las características básicas de la población de ascendencia africana en Foshan.

\subsubsection{Existe una alta similitud entre los grupos étnicos de África en Foshan}

A través del análisis estadístico de las personas entrevistadas que viven en las dos ciudades, Foshan y Guangzhou, los resultados reflejan que existe una mayor semejanza entre los grupos africanos que viven en Foshan frente a los que 
Tabla 2. La información del cuestionario de la parte de Foshan

\begin{tabular}{|c|c|c|c|}
\hline Indicador & & Muestra & Porcentaje \\
\hline \multirow[t]{3}{*}{ Sexo } & Masculino & 62 & $97 \%$ \\
\hline & Femenino & 0 & 0 \\
\hline & Sin información & 2 & $3 \%$ \\
\hline \multirow[t]{5}{*}{ Edad } & Menos de 18 años & 0 & 0 \\
\hline & 18-29 años & 37 & $57,8 \%$ \\
\hline & 30-39 años & 20 & $31,2 \%$ \\
\hline & 40-49 años & 4 & $6,3 \%$ \\
\hline & Sin información & 3 & $4,7 \%$ \\
\hline \multirow[t]{4}{*}{ Religión } & Cristiana & 60 & $93,7 \%$ \\
\hline & Musulmana & 1 & $1,6 \%$ \\
\hline & No & 1 & $1,6 \%$ \\
\hline & Otra & 2 & $3,1 \%$ \\
\hline \multirow[t]{6}{*}{ Nivel de educación } & No & 1 & $1,6 \%$ \\
\hline & Escuela primaria o equivalente & 0 & 0 \\
\hline & Escuela secundaria o equivalente & 24 & $37,5 \%$ \\
\hline & Bachillerato o equivalente & 17 & $26,6 \%$ \\
\hline & Universitario & 18 & $28,1 \%$ \\
\hline & Sin información & 4 & $6,2 \%$ \\
\hline \multirow[t]{4}{*}{ Estado civil } & Casado & 13 & $20 \%$ \\
\hline & Soltero & 41 & $64 \%$ \\
\hline & Tiene pareja fija & 7 & $11 \%$ \\
\hline & Sin información & 3 & $5 \%$ \\
\hline \multirow[t]{4}{*}{ Tipo de visado } & Visado de turista & 8 & $12,5 \%$ \\
\hline & Visado de negocio & 52 & $81,3 \%$ \\
\hline & Visado de trabajo & 1 & $1,6 \%$ \\
\hline & Sin información & 3 & $4,6 \%$ \\
\hline
\end{tabular}

Fuente: elaboración propia a partir de encuesta.

habitan en Guangzhou. En primer lugar, el país original de los grupos africanos que viven en Foshan es más concreto respecto a los que viven en Guangzhou, pues se concentra en Nigeria $(84,4 \%)$ (Figura 3).

En segundo lugar, con respecto a la población africana de Guangzhou, Foshan posee un colectivo africano más joven y con una alta tasa de solteros. $\mathrm{Si}$, en Guangzhou, un 22,7\% de ellos tiene una edad superior a 40 años, dicho porcentaje ronda el 10,8\% en Foshan, donde predomina el colectivo masculino y de jóvenes entre los 18 y los 29 años (51,4\%) (figura 4). Además, la mayoría de las personas entrevistadas en Foshan están solteras (un 69\%), cuando dicho porcentaje se limita a un 33\% en Guangzhou (figura 5). En el caso de los africanos que tienen pareja, se observa un paralelismo entre los de Guangzhou y los de Foshan, pues, en ambos casos, la mayoría de sus parejas provienen de países africanos y en menor medida del resto de China y de otros países (figuras 6 y 7 ). 
Figura 3. País de origen de los inmigrantes africanos de Guangzhou y Foshan

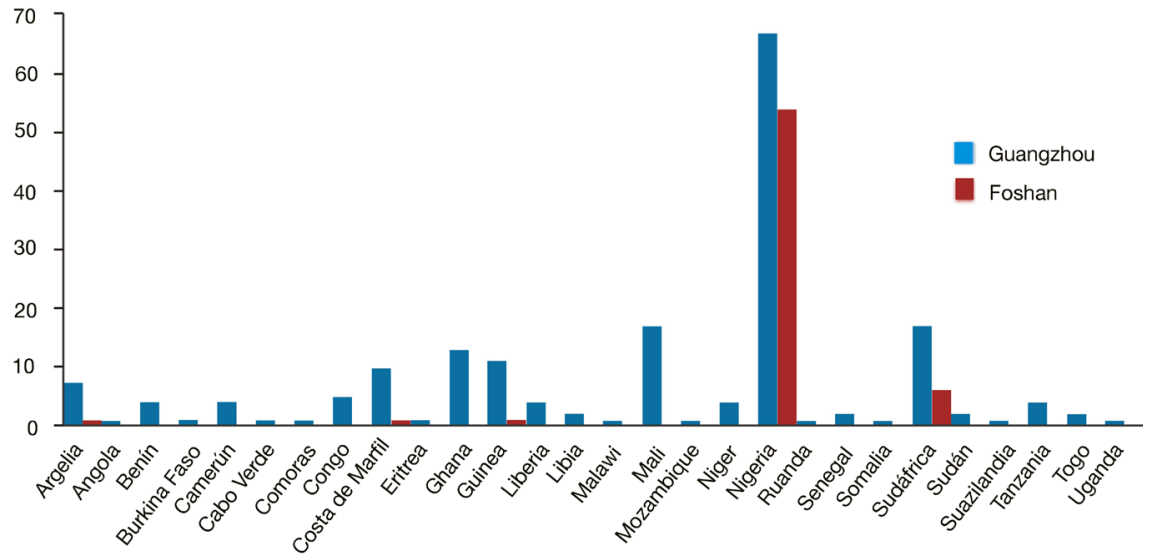

Fuente: elaboración propia a partir de encuesta.

Figura 4. Distribución por edad de los africanos en Guangzhou y Foshan

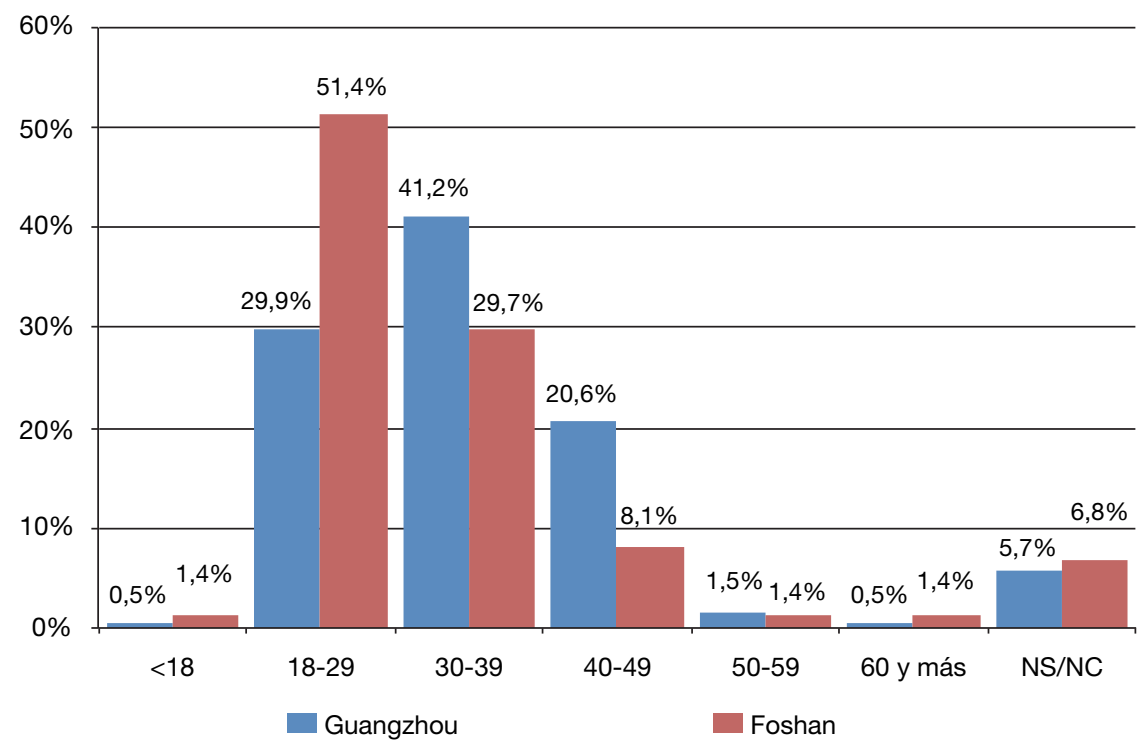

Fuente: elaboración propia a partir de encuesta.

En tercer lugar, al analizar el nivel académico, se advierte que el de Foshan es más bajo que el de Guangzhou. La figura 8 muestra como, en Guangzhou, existe un predominio de africanos con estudios universitarios 
Figura 5. Distribución por estado civil de los africanos en Guangzhou y Foshan

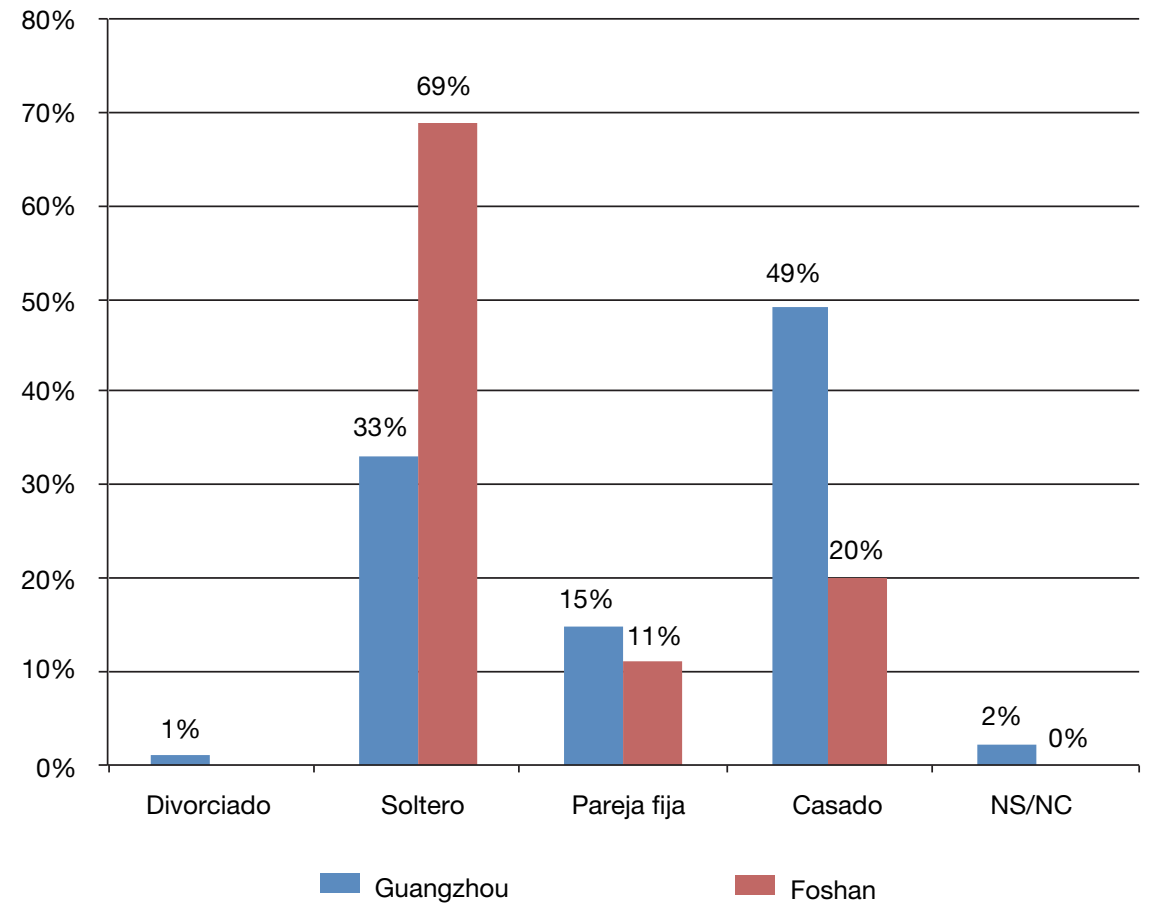

Fuente: elaboración propia a partir de encuesta.

Figura 6. Estado civil de los africanos en Foshan

$1 \%$

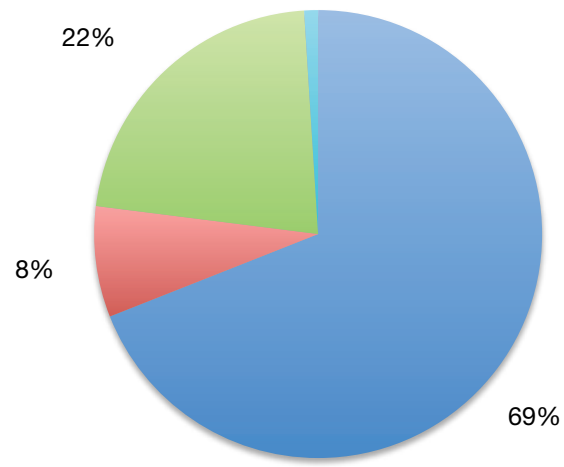

Soltero

Con esposa china

Con esposa africana

Divorciado

Otra

Fuente: elaboración propia a partir de encuesta. 
Figura 7. Estado civil de los africanos en Guangzhou

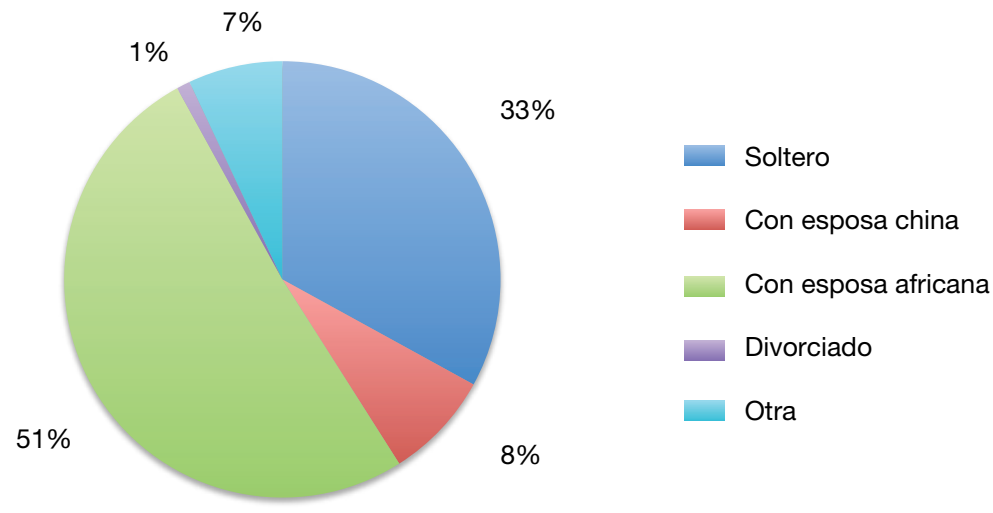

Fuente: elaboración propia a partir de encuesta.

Figura 8. Nivel académico

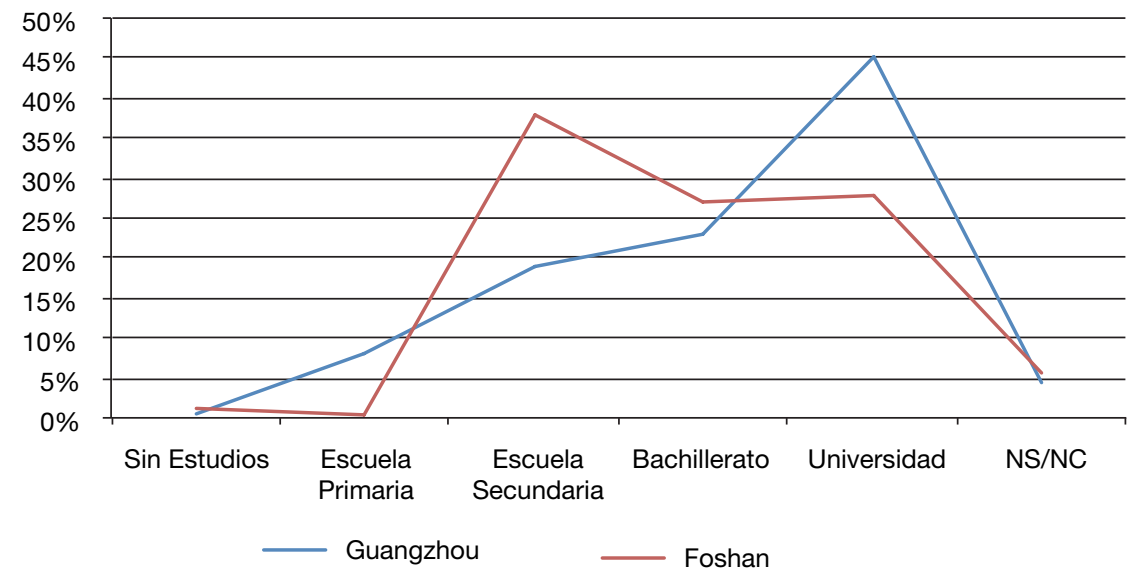

Fuente: elaboración propia a partir de encuesta.

o de bachillerato. Mientras que, en Guangzhou, un $42 \%$ tiene el nivel de bachillerato o de secundaria, en Foshan, dicho porcentaje alcanza el 65\%. En cuanto a los ingresos económicos mensuales, cabe señalar que los de Foshan son relativamente más bajos (figura 9). Finalmente, del cuestionario se deduce que la mayoría de los africanos que viven en Foshan son inmigrantes ilegales, su visado está fuera de la fecha de caducidad válida, mientras que los africanos residentes en Guangzhou presentan una situación legal más compleja. 
Figura 9. Ingresos mensuales (en yuanes)

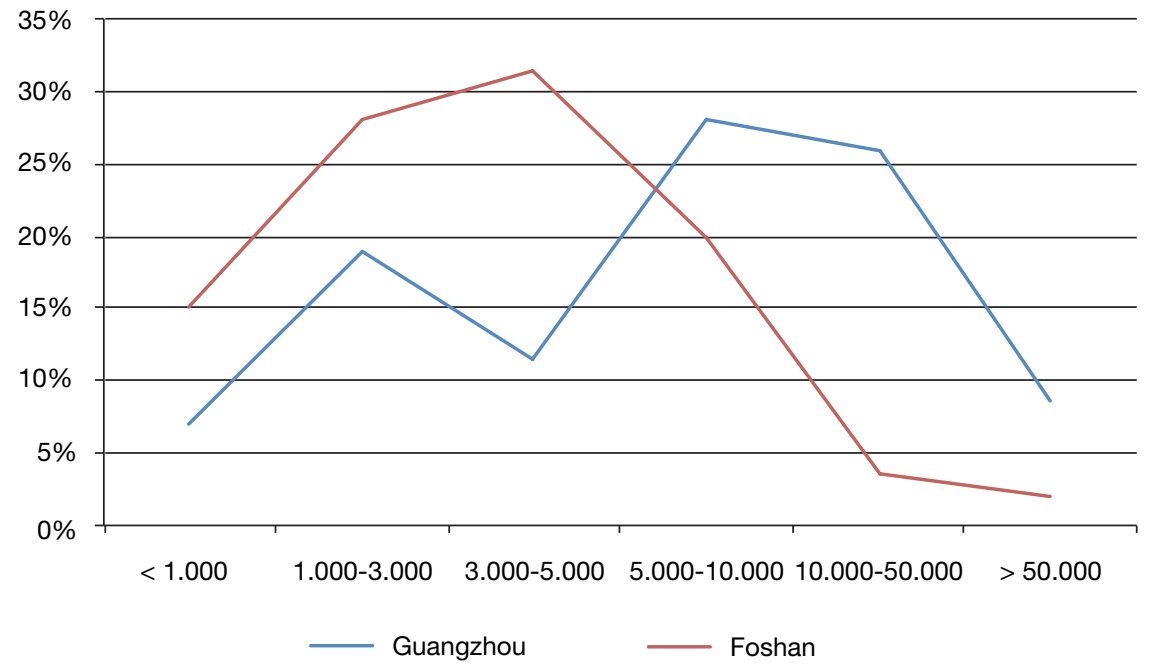

Fuente: elaboración propia a partir de encuesta.

Figura 10. El año de llegada a China

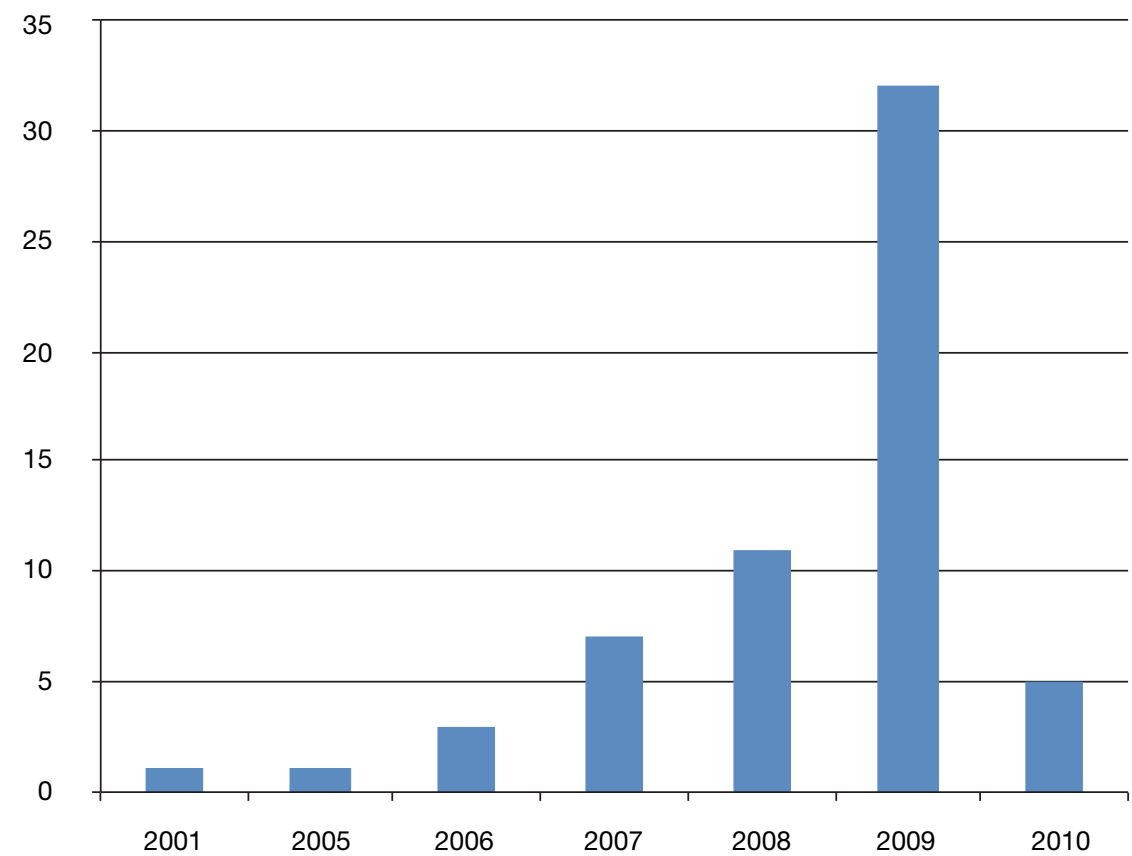

Fuente: elaboración propia a partir de encuesta. 
Figura 11. El año de llegada a Foshan por primera vez

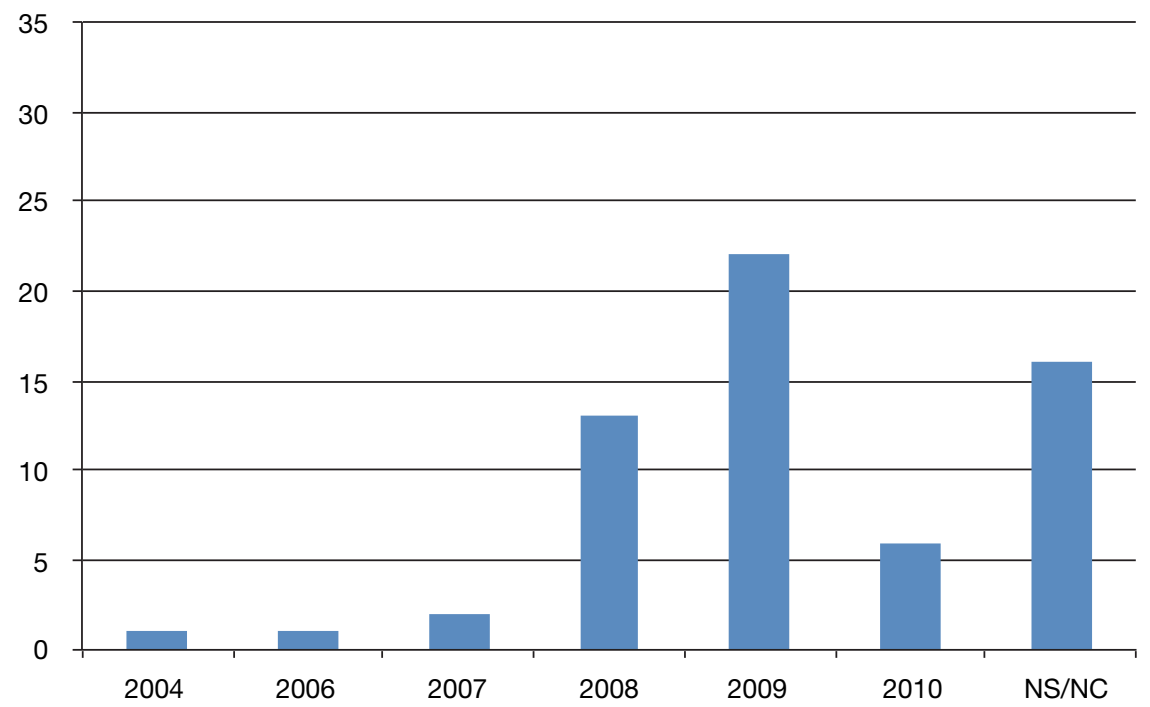

Fuente: elaboración propia a partir de encuesta.

3.1.2. Debido a la regulación gubernamental y a razones económicas, la mayoría de los grupos étnicos están obligados a mudarse y se marchan de Guangzhou Según los datos aportados por el cuestionario realizado en Foshan durante el año 2010, desde el 2006, se observa una llegada paulatina de africanos a China, nivel que alcanza su punto álgido en el año 2009, cuando se registra el 52\% del total (figura 10). Estos datos se constatan al analizar el tiempo de residencia, pues un $67 \%$ de ellos empezaron a vivir en Foshan después de 2008, si bien fue en 2009 cuando se alcanzó el momento culminante, al registrar un 34,4\% (figura 11). En consecuencia, y a pesar de que el cuestionario se realizó en abril de 2010 y no se han podido recoger datos posteriores a dicha fecha, se puede afirmar que existe un rápido incremento de población africana en Foshan desde el año 2008. Por otra parte, la información recogida en las entrevistas sigue corroborando dicho incremento, al mismo tiempo que permite observar que, entre los africanos que viven actualmente en Foshan, predominan los de carácter ilegal. Algunos de ellos se trasladaron desde Guangzhou, mientras que otros llegaron directamente a Foshan desde África para trabajar, y lo hicieron a través de redes de amigos.

Finalmente, cuando se pregunta a los africanos entrevistados en Foshan sobre las razones por las que han migrado, destacan dos principales: la migración voluntaria y la migración obligatoria. La migración voluntaria obedece a que, debido a causas laborales, deben residir en Foshan. Dicha opción representa un 19\% del total. Entre las respuestas dadas, están algunas como: «Abrí la tienda en Foshan», "Era un exempresario y ahora soy un empleado en Foshan» y "Hasta 
Figura 12. Las causas para vivir en Foshan

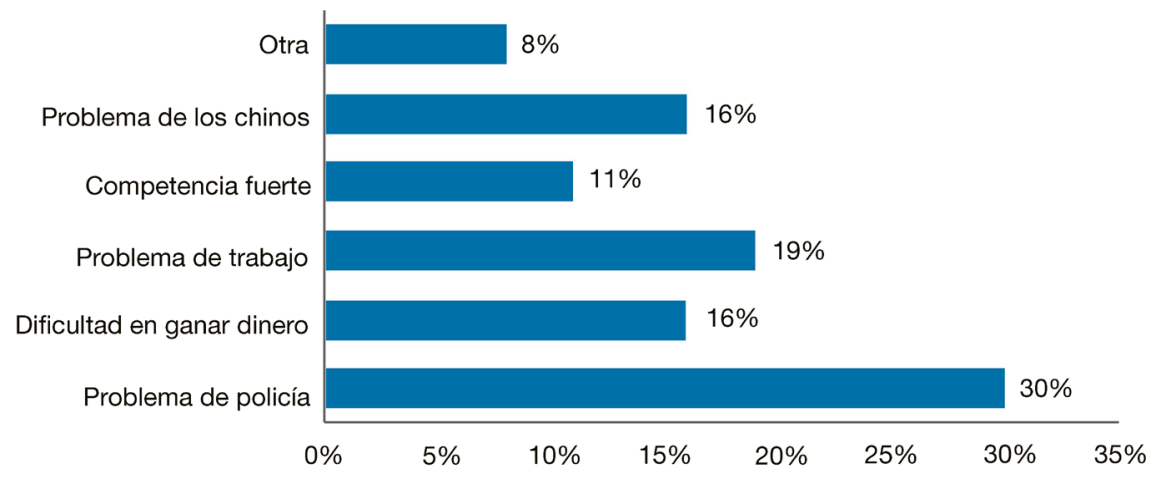

Fuente: elaboración propia a partir de encuesta.

que la economía se recupere, hago negocios aquí», etc. La migración obligatoria obedece a factores externos, y entre las razones principales, se encuentran los problemas con la policía (30\%), pues «La policía de Guangzhou los detiene e intercepta», "La policía registra sus pasaportes y visados» y «El Gobierno está especialmente preocupado por los africanos». Un 19\% tiene problemas en el trabajo, mientras que, para un 16\% de los africanos, el problema está en el conflicto con la población autóctona china y en la dificultad para ganar dinero, por lo que no pueden hacer frente al coste de la vida y se trasladan a Foshan. Por su parte, para un $11 \%$ de los entrevistados, el motivo por el que migran es la fuerte competencia (figura 12). En consecuencia, se puede observar que la mayoría de los africanos se ve obligada a migrar a Foshan debido a los factores externos, incluyendo las causas económicas y la actitud del Gobierno, etc.

\subsection{Las características de movilidad}

Como se apuntó, el análisis realizado muestra que, después del año 2008, la población africana aumentó rápidamente en Foshan. La mayoría de estos africanos son inmigrantes ilegales o con capacidad económica débil. Para evadir la actuación de la policía o ahorrar dinero, viven en el área de Huangqi de Foshan, donde forman grupos «especiales» con algunas características nuevas en relación con otros inmigrantes. Se diferencian de los inmigrantes africanos tradicionales residentes en Guangzhou en aspectos como su elevada movilidad y flexibilidad en relación con el espacio residencial, la forma de vida, la situación legal y sus relaciones de red, aspectos que, en ocasiones, resultan incompatibles con la mayor parte del entorno institucional local.

\subsubsection{La transformación rápida del espacio oculto}

El hecho de que el Gobierno de Guangzhou rechace en gran medida a los africanos, dado que la mayoría no tiene visado legal ni permiso de residencia, provoca 
que estos se vean obligados a enfrentarse a condiciones de vida muy difíciles, un hecho que ha provocado movimientos centrípetos de africanos que huyen de Guangzhou en busca de un nuevo lugar donde vivir. Foshan, como ciudad vecina de Guangzhou, se ha convertido en un foco receptor, tanto por sus excelentes conexiones de transporte, como por la actitud relativamente benévola del Gobierno local. Según las entrevistas, cuando la policía de Foshan realiza sus tareas, si encuentra que los visados están expirados, les ordena salir en lugar de detenerlos en la comisaría de policía. Sin embargo, la mayoría de los inmigrantes africanos considera que la policía en Foshan es más «humanitaria» que en Guangzhou, que «todo el día está llena de policías», a los que caracterizan como «horribles», "terroristas" y "con falta de humanidad». Esto explica que los inmigrantes africanos aprovechen las diferencias en la actitud mostrada por parte de los dos gobiernos locales y la aplicación diferente de los aspectos jurídicos para preferir residir en Foshan, de modo que la forma de lucha del colectivo contra la represión estratégica del Gobierno de Guangzhou se materializa a través de su propia movilidad. Sin embargo, desde el año 2010 y el comienzo de los Juegos Asiáticos de Guangzhou, el Gobierno de Foshan, en respuesta a la llamada del de Guangzhou, comenzó a reforzar la aplicación de la Ley de inmigración, llevando a cabo frecuentes redadas en las áreas que acogen a las comunidades de inmigrantes africanos. En mayo de 2010, un masivo grupo de inmigrantes se vio obligado a abandonar Foshan. En consecuencia, los inmigrantes africanos que no tienen el permiso de residencia en su poder prefieren marcharse a otras aldeas más aisladas y alejadas del resto de los inmigrantes para vivir, con el fin de eludir la atención de la policía y prevenir repatriaciones. Un agente de seguridad de un barrio en que habitan muchos africanos dijo lo siguiente:

Probablemente, fue a partir del 2008 cuando comenzaron a vivir los negros en este barrio, aunque el número que existía entonces era relativamente

Figura 13. Distribución de las residencias y de las instalaciones de las comunidades étnicas en el año 2010 (relativamente concentradas)

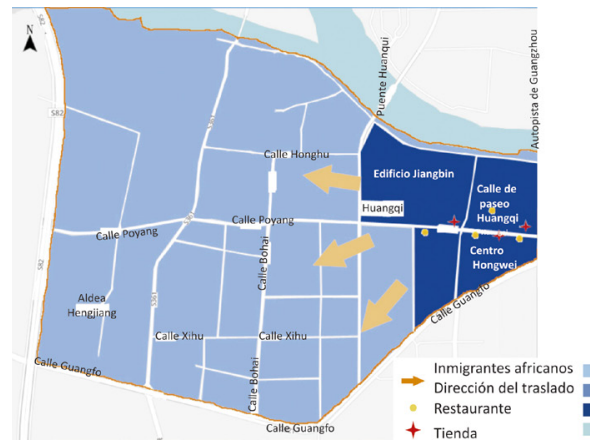

Fuente: elaboración propia a partir de encuesta.
Figura 14. Distribución de las residencias y de las instalaciones de las comunidades étnicas en el año 2014 (relativamente dispersas y parcialmente concentradas)

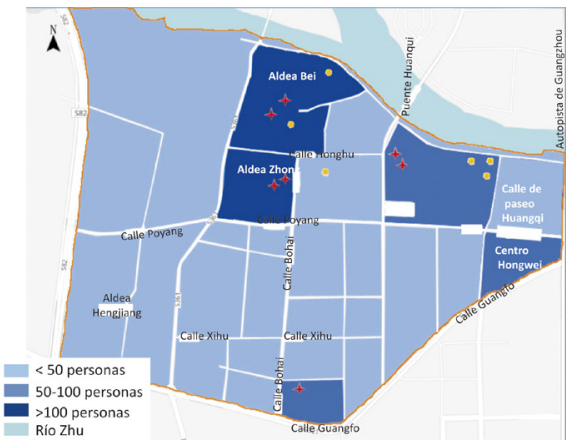


pequeño. Fue a partir de 2009 y 2010 cuando el número aumentó progresivamente, hasta que alcanzó más de 100 en 2010, de modo que, en cada edificio, se podían contabilizar varios negros residiendo en el mismo. Luego, desde el año 2011, la policía empezó a realizar registros frecuentes, casi cada dos meses; llamaban a las puertas para registrar sus documentos y comprobar si el pasaporte había caducado. El mes pasado, alrededor del día 15, vinieron más de 40 policías vestidos de civil, iban de casa en casa buscando inmigrantes, y algunos propietarios les dijeron dónde vivían los negros. Así que muchos de ellos se mudaron por esta razón. Los que se quedan son los que tienen documentos válidos, probablemente más de 10. (Nota de entrevista, octubre de 2013)

Ahora están dispersos en lugares más aislados, casas rurales o sitios más remotos. Como en Jinshazhou, donde los veo salir de casas rurales con frecuencia. (Nota de entrevista, octubre de 2013)

En consecuencia, se sabe que las comunidades de inmigrantes africanos van dispersándose, debido a las frecuentes redadas de la policía, y huyen a las aldeas de Foshan. De este modo, la estructura residencial de los inmigrantes africanos va pasando progresivamente de una concentración relativa a una fase relativamente dispersa y parcialmente concentrada (figuras 13 y 14).

\subsubsection{La forma de vivir en "suburbios dinámicos"}

Para ganarse la vida, los grupos de inmigrantes africanos dedicados al comercio adoptan todas las medidas necesarias a fin de conseguir fuentes de ingresos. Sin embargo, dado que los ilegales tienen severamente restringido el trasladarse a otras ciudades, los comerciantes africanos dedicados a la circulación de mercancías se han visto obligados a comprar productos fuera de Foshan y transportarlos a su territorio. Se aprovechan del desequilibrio en diferentes tiempos y espacios de la Ley de inmigración de China para reforzar su movilidad. Por ejemplo, con respecto al tiempo, el riesgo varía en relación con la amenaza proveniente de la policía: normalmente, es más seguro viajar durante la madrugada, a medianoche y a la hora de comer, periodos durante los cuales no trabajan los policías. Además, creen que quedarse en casa sin salir tampoco es una medida segura, porque la policía va a buscarlos de vez en cuando. Por eso, a fin de enfrentarse a dicha situación, muchos eligen salir temprano y regresar tarde, para así hacerles creer que son residentes con trabajo y respetan la ley. De esa manera, ha ido surgiendo una forma de vida conocida como «suburbanización dinámica», en la que las facilidades del tráfico con Guangzhou y su proximidad han favorecido que Foshan se considere uno de sus suburbios, pero en la que, sin embargo, los africanos prefieren desplazarse a Guangzhou para comprar las mercancías. Normalmente, se mezclan con algún grupo móvil de trabajadores que permanece en Guangzhou durante el día y regresa a Foshan por la noche. Así, gestionan sus negocios y evitan la redada de la policía. «Normalmente, salen a las seis de la mañana y algunos no regresan hasta la una o las dos de la madrugada» (nota de entrevista, diciembre de 2013). "Hago compras todos 
los días en el mercado del embarcadero Huangsha de Guangzhou, donde hay muchos puestos que venden teléfonos móviles. Voy para allá a las cuatro o a las cinco de la mañana y regreso en taxi a las doce de la noche» (nota de entrevista, marzo de 2014).

Por lo que respecta a las formas de locomoción que emplean, debido a la falta de papeles válidos, no pueden permitirse coger un tren o el avión, con lo cual se limitan a utilizar el coche, aunque ello suponga mucho tiempo de desplazamiento. Para no encontrarse con la policía, tampoco suelen utilizar los autobuses públicos ni el metro. La única alternativa es coger un taxi que les cobra más y que encarece el coste final de la mercancía. En todo caso, a pesar de que dichas medidas les sirven para defenderse de las políticas locales, no se pueden ignorar las pérdidas que les ocasionan.

\subsubsection{La situación legal}

Los africanos que viven en Guangzhou se dividen principalmente en tres tipos: comerciantes de estancia breve, inmigrantes con residencia legal e inmigrantes ilegales (sin visado ni permiso de residencia válidos). La situación legal de los africanos suele oscilar repetidamente entre esos tres tipos: la mayoría de ellos se desplaza hasta China con visado de negocio o visado de turista con una estancia breve de 30 días. Pasado dicho plazo, mientras muchos de ellos se convierten en inmigrantes ilegales, debido a que no pueden pagar la costosa cuota de renovación (en torno a 10.000 yuanes $^{2}$ ), cuando el visado está terminando, otros consiguen el permiso de estancia a través de la renovación de su visado, pero deben renovar anualmente el permiso de residencia, lo que provoca que numerosos africanos no puedan actualizarlo continuamente y se conviertan en inmigrantes ilegales de nuevo.

Según la nueva Ley de inmigración, si los inmigrantes ilegales quieren irse de China, tienen que abonar 5.000 yuanes de multa para solicitar el visado de salida, enseñar su pasaporte y pagar el vuelo de repatriación. Además, al aceptar la multa y solicitar el visado de salida, corren el riesgo de entrar en la cárcel por haber violado las leyes y los reglamentos de inmigración. Dicho riesgo, unido a las costosas tarifas y multas, hace que los inmigrantes ilegales recurran a otras medidas para enfrentarse a esta dura situación. Una de ellas es ir regularmente a Hong Kong u otros lugares para renovar el visado de treinta días, pero tienen que pagar el viaje y la tarifa de la renovación. Algunos africanos deciden estudiar en las universidades, con el fin de conseguir el visado de estudiante y aprender chino. La ventaja es que así pueden quedarse legalmente en China y esto es favorable para sus negocios, el inconveniente está en que estudiar en escuelas internacionales es extremadamente caro. Uno de los encuestados estudió en una escuela de Shenzhen pagando 100.000 yuanes al año. Le costó mucho dinero y tiempo y, al final, tuvo que abandonar la carrera, con lo que volvió a convertirse en inmigrante ilegal y pasaba todo el día oculto.

2. 1 yuan equivale a 0,14 euros, con lo que 10.000 yuanes serían 1.400 euros. 
Figura 15. Total de africanos que se dirigen a otras ciudades chinas para comercio

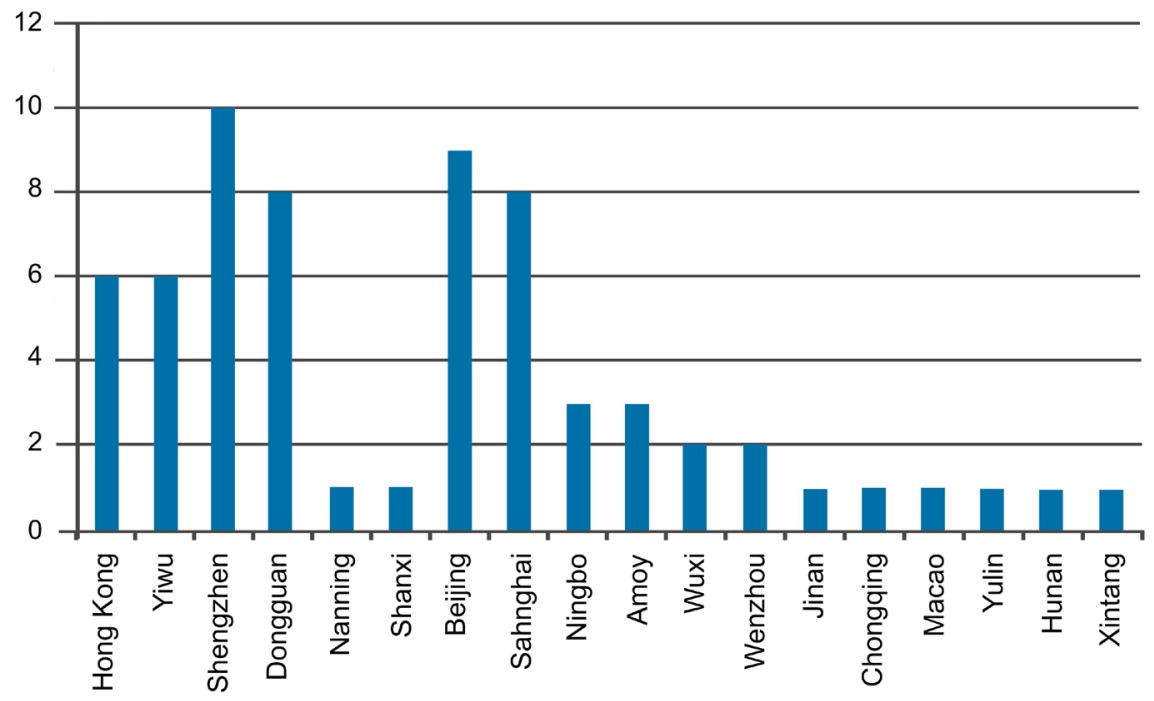

Fuente: elaboración propia a partir de encuesta.

Estudié en una universidad de Shenzhen. Pude quedarme en China con el visado de estudiante. La matrícula era demasiado cara, 100.000 yuanes al año, y no tenía tiempo para dedicarme a mis negocios. Por eso dejé la universidad. (Nota de entrevista, diciembre de 2013)

Voy una vez al mes a Macao para actualizar mi visado. Cada vez cuesta entre 2.000 y 3.000 yuanes. (Nota de entrevista, marzo de 2014)

Otra medida que se adopta es comprar un visado nuevo en los mercados negros de China. Normalmente, el de seis meses cuesta 15.000 yuanes (2.066 euros), mientras que, por el de otros países africanos, piden 10.000 yuanes (1.400 euros). Los mercados negros están manejados por los intermediarios chinos. Llevan a los clientes africanos a lugares aislados, donde no es fácil ser capturados y donde los funcionarios pueden ser sobornados con más facilidad. Sin embargo, corren un gran riesgo, porque no pueden hacer nada hasta que los intermediarios les manden el visado con éxito.

\subsubsection{La variedad de lugares de negocio}

Generalmente, la profesión de comerciante demanda un alto grado de movilidad. Requiere desplazarse entre muchos países y entre muchas zonas para establecer y mantener las relaciones comerciales con intermediarios, fabricantes, clientes, etc. Por eso, aunque la mayoría se decanta por mantener sus relaciones con un único lugar, existen otros que poseen una red de negocio que atraviesa muchos países, con lo que forman un flujo trasnacional altamente 
Figura 16. Distribución de la red comercial de los africanos que viven en Foshan

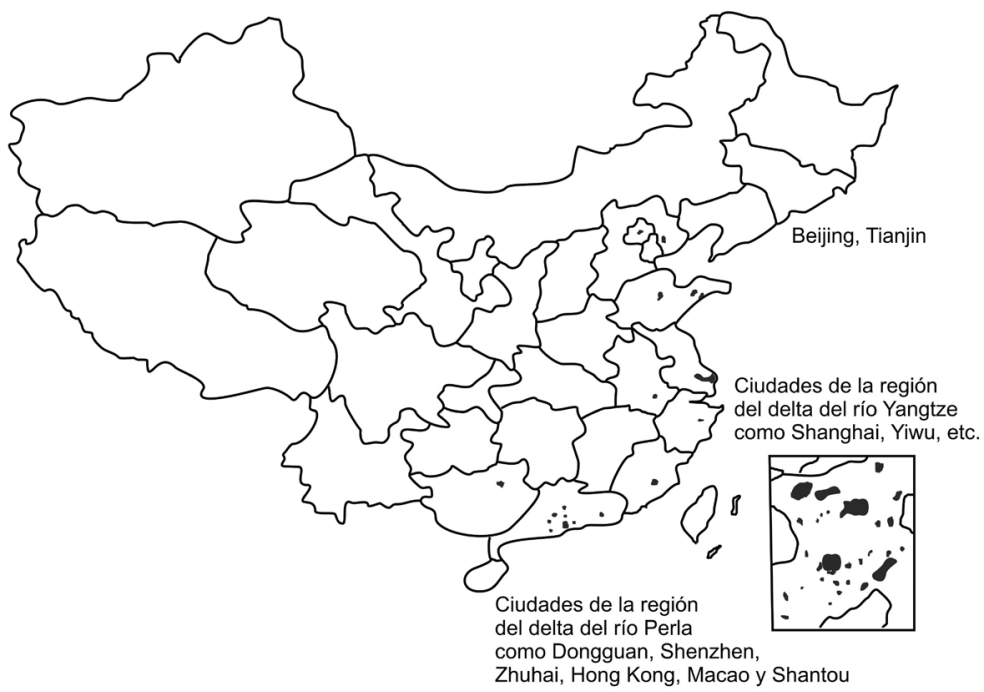

Fuente: elaboración propia a partir de encuesta.

cíclico. También están aquellos comerciantes africanos que se desplazan hasta las ciudades chinas en las que el control es más laxo (figura 15), para ir directamente a las fábricas y así reservar y/o comprar las mercancías. En ellas, son mejor recibidos que en Guangzhou y por ello sus estancias suelen ser largas o breves pero continuas. La mayoría de dichas ciudades se concentra en la región del delta del río Perla — Shenzhen, Dongguan, Zhongshan y Hong Kongy del delta del río Yangtze — Shanghai y Yiwu - (figura 16).

\subsubsection{Red de relaciones más compleja y diversa}

Debido a las restricciones externas impuestas por el espacio político, los inmigrantes africanos están empezando a construir sus propias redes para conseguir una mayor flexibilidad en sus comportamientos y hacer frente a los continuos desafíos (Dong, 2009). Sobresale el hecho de que muchos africanos procuran ganarse el favor de las mujeres chinas y establecer relaciones con ellas para vivir mejor en las ciudades. A través de ellas, consiguen informaciones para prevenir las acciones de la policía, buscar alojamientos y trabajos, comunicarse con los socios o hacer negocios utilizando su franquicia. Dos chinas entrevistadas son esposas de nigerianos. A causa de los documentos caducados, sus esposos no podían seguir haciendo negocios en Guangzhou, por lo tanto, se fueron a Foshan con ellas. Abrieron un restaurante y un bar utilizando su franquicia legal de operación. En este contexto, surge un nuevo espacio de relación intercultural, reflejado en la relación comercial y de amistad entre la comunidad china y la africana: 
A los africanos, les gusta ligar con las chicas chinas porque les avisan cuando viene la policía. (Nota de entrevista, octubre de 2013)

Mantenemos juntos este bar mi marido y yo. Como él no tiene derecho de operación en China, lo consigo yo y ahora somos socios. (Nota de entrevista, noviembre de 2013)

Respecto a la residencia, puesto que cada vez más población africana se reúne en los suburbios étnicos de Foshan, se está formando una nueva relación económica entre los nativos, los residentes procedentes de otros lugares y la comunidad africana. En cierta medida, han aumentado las oportunidades económicas para los nativos y también se ha ampliado el espacio y las instalaciones de servicio para la comunidad africana.

Durante el periodo de transición, una gran cantidad de población africana se trasladó de los barrios de Guangzhou a las aldeas suburbanas de la ciudad. Desde entonces, los nativos han ido construyendo los llamados «apartamentos étnicos» en sus propiedades. Se trata de unas viviendas destinadas a personas procedentes de otras ciudades, que, curiosamente, no son las destinatarias finales, pues, una vez que formalizan el contrato de alquiler con el nativo, vuelven a alquilarlas a africanos, con lo que obtienen enormes beneficios. Normalmente, los alquileres son por habitación y mes. Cada habitación tiene una superficie de entre 10 a 20 metros cuadrados y el precio oscila entre los 700 y los 1.200 yuanes, de forma que pueden llegar a obtener más de 100.000 yuanes al año. Además, en esta relación económica, los africanos pagan el alquiler a los chinos a cambio de algunos servicios cotidianos, como la gestión de la electricidad, el agua y la seguridad. Al mismo tiempo, los chinos procedentes de otras ciudades ofrecen espacios a los africanos para vivir, y son ellos quienes pagan el alquiler a los nativos. En todo caso, esta relación económica tiene un alto grado de informalidad, pues los africanos que viven en dichos apartamentos no poseen registro ni documentación legal alguna, con lo que se produce una relación de alta dependencia respecto a la persona que alquila (figura 17). Aún así, la

Figura 17. La relación económica de los «apartamentos étnicos»

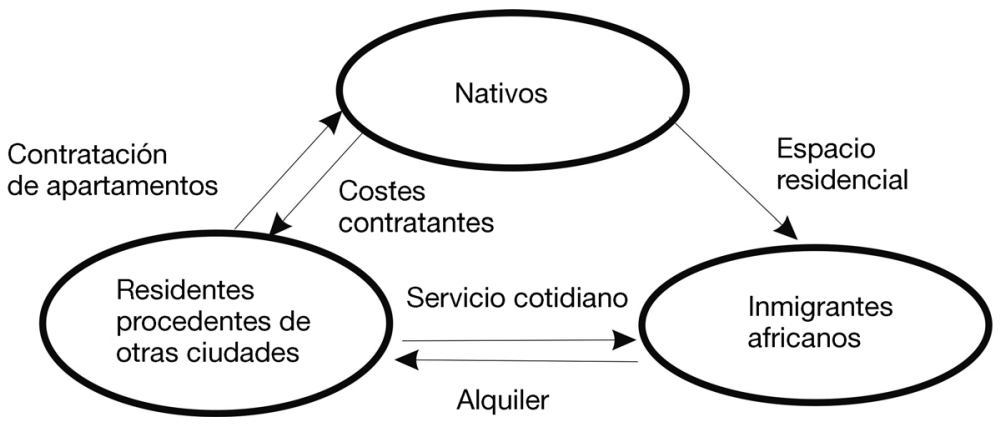

Fuente: elaboración propia. 
aparición de estos vínculos económicos en los suburbios étnicos atrae más africanos cada día.

Una vez los grupos étnicos han alcanzado cierta magnitud, se observa que empiezan a aparecer comercios y servicios destinados a los mismos. La llegada de africanos a Huangqi ha provocado el surgimiento de un pequeño número de restaurantes y bares africanos. No obstante, a diferencia de lo que sucede con los suburbios étnicos occidentales, la perspectiva de futuro no es optimista respecto al desarrollo económico de los suburbios africanos de Foshan. Según la encuesta, hay muy pocas empresas étnicas en los suburbios africanos. Casi todas se dedican a realizar negocios a pequeña escala con dos o tres empleados que prestan servicio a los clientes étnicos. La mayoría de estos negocios son fruto de la cooperación entre chinos y africanos, con una relación social especial entre ellos (por ejemplo: el matrimonio). Entre las causas, están las condiciones competitivas del mercado, las restricciones comerciales y la falta de dinamismo mercantil en dichos suburbios. A ello se une que la mayoría de los africanos en Foshan no dispone de derechos legales para hacer negocios, y sus empresas no poseen la licencia ni la certificación necesarias para operar (a pesar de que existen algunas operaciones sin licencia). Se les prohíbe hacer negocios en China, de ahí su alta dependencia de las franquicias de los nativos chinos para poder aprovechar alguna oportunidad económica:

Administramos juntos este restaurante mi esposa y yo. Es china y puede conseguir la franquicia fácilmente. Como yo no tengo el derecho de obtenerla, consigo la licencia del restaurante a través de mi esposa. (Nota de entrevista, noviembre de 2013)

En el año 2011, mi esposo nigeriano y yo abrimos un bar en la calle de paseo en Huangqi. Vinimos de nuevo el año 2012 y actualmente administro el negocio de aquí. Empleamos a unos amigos suyos como cocineros y camareros. (Nota de entrevista, diciembre de 2013)

\section{Conclusiones}

A pesar de que la mayoría de la población africana de Foshan es ilegal y sufre una gran debilidad económica, si se compara con los grupos africanos de Guangzhou, es mucho más dinámica y diversa en lo que atañe al espacio residencial, a la forma de vivir, a la situación legal y al lugar de negocio. Un dinamismo que es intrínseco a las propias características del colectivo africano, pues su condición de inmigrantes ilegales los lleva a trasladarse a espacios residenciales más ocultos, lo que ha dado lugar a la aparición de nuevas pautas de movilidad y de un nuevo tipo de vida que se ha denominado «suburbanización dinámica». Por otra parte, ya sea por estos factores, por los problemas causados por su estatus migratorio o por las características básicas de los comerciantes africanos, estamos asistiendo a una diversificación de lugares de negocio, a la creación de un modelo de movilidad cada vez más complejo y a la aparición de nuevas redes de relación social (figura 18). 
Figura 18. Sistema con características migratorias de los suburbios étnicos

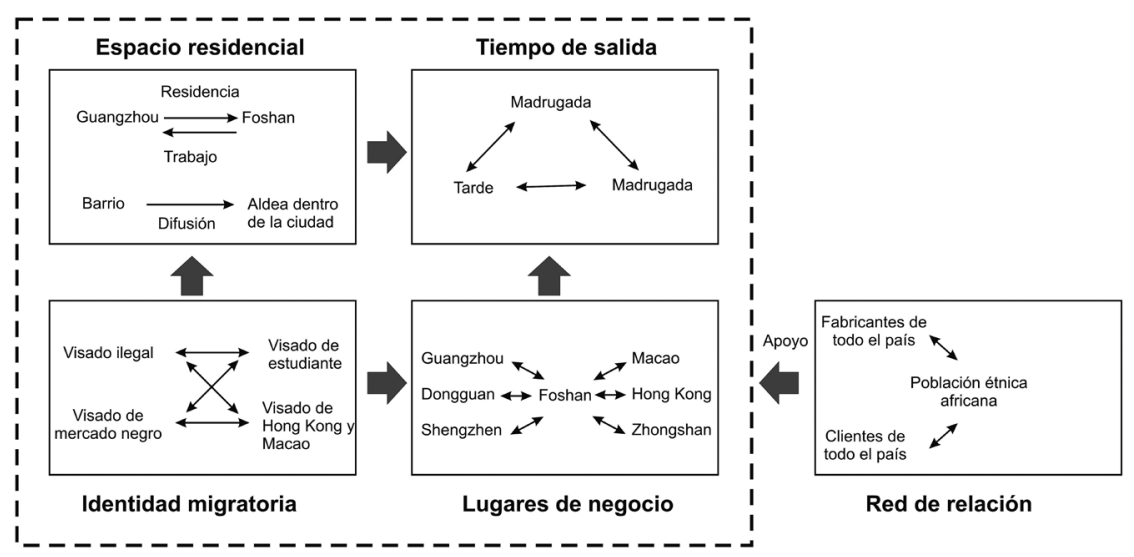

Fuente: elaboración propia.

El suburbio étnico se ha convertido en una alternativa a los enclaves étnicos tradicionales del espacio interior de la ciudad, con lo que se transforman en "puertos de entrada" destacados para inmigrantes. Asimismo, la proliferación de relaciones sociales y económicas diversas ha favorecido su posicionamiento como enclaves destacados en un contexto socioeconómico y político particular. Estas relaciones se reflejan en una dinámica intensa que varía rápidamente de acuerdo con los cambios del ambiente externo, lo que produce un espacio urbano social «corriente». De este modo, los suburbios étnicos están registrando una transformación de acuerdo con el cambio del ambiente político y económico de China, lo que puede llegar a generar suburbios étnicos dinámicos.

\section{Referencias bibliográficas}

Bodomo, Adams y MA, Enyu (2010). «From Guangzhou to Yiwu: Emerging facets of the African Diaspora in China». International Journal of African Renaissance Studies -Multi-, Inter- and Transdisciplinarity [en línea], 5 (2), 283-289. $<$ http://dx.doi.org/10.1080/18186874.2010.534854>

- (2012). «We are what we eat: Food in the process of community formation and identity shaping among African traders in Guangzhou and Yiwu». African Diaspora [en línea], 5 (1), 3-26. <http://dx.doi.org/10.1163/187254612X646198>

CASTELls, Manuel (2000). The rise of the network society. Oxford: Blackwell.

Chen, Yupeng (2012). «La formación del capital social y los barrios de los extranjeros en las ciudades: Comparación de un barrio internacional de Yiwu y el Barrio Africano de Guangzhou». Pionero, 12 (4), 114-115.

Connell, J. e Ip, A. (1981). «The Chinese in Sydney: From Chinatown to Surburbia». Asian Profile, 9 (4), 291-308. 
Dong, Liqun (2009). "Las redes sociales y la integración social de los nuevos inmigrantes urbanos, por ejemplo: los inmigrantes de Ningbo». Prensa del Colegio Tecnológico y de Entrenamiento de Huainan, 9 (4), 105-110.

FANG, Ying y Liang, Ningxin (2010). «Reglas de la distribución de los habitantes extranjeros y sus factores: Estudio de Guangzhou». Prensa de la Universidad de Guangzhou (la versión de ciencias sociales), 9 (10), 48-54.

Guangtian, Kangsheng (2005). Migrantes y ciudades. Beijing: Editorial Comercial.

Han, Huamei (2013). "Individual Grassroots Multilingualism in Africa Town in Guangzhou: The Role of States in Globalisation». International Multilingual Research Journal [en línea], 7 (1), 83-97. <http://dx.doi.org/10.1080/19313152.2013.746803>

Hannam, Kevin; Sheller, Mimi y Urry, John (2006). «Editorial: Mobilities, Immobilities and Moorings». Mobilities [en línea], 1 (1), 1-22. <http://dx.doi.org/10.1080/17450100500489189>

Harvey, David (1989). The Condition of Postmodernity. Oxford: Blackwell.

- (2003). The New Imperialism. Oxford: Oxford University Press.

Haugen, Heidi Østbø (2012). «Nigerians in China: A Second State of Immobility». International Migration [en línea], 50 (2), 65-80. <http://dx.doi.org/10.1111/j.1468-2435.2011.00713.x>

HEBO (2008). «Características e integración de los barrios coreanos en Beijing: Pueblo Coreano de Wangjing». Problemas Urbanos, 10, 59-64.

KIM, Harris (2003). «Ethnic Enclave Economy in Urban China: The Korean Immigrants in Yanbian». Ethnic and Racial Studies [en línea], 26 (5), 802-828. <http://dx.doi.org/10.1080/0141987032000109041>

Kwong, Peter (1987). The New Chinatown. Nueva York: Frarrar, Straus and Girous.

LI, Wei (2006). From Urban Enclave to Ethnic Suburb: New Asian Communities in Pacific Rim Countries. Honolulu: University of Hawaii Press.

Liu, Yungang y TAN, Yuwen (2010). «Dinámica migratoria de Japón bajo la globalización». Geografía Mundial, 19 (3), 62-71.

Liu, Yungang; TAN, Yuwen y ZHOU, Wenting (2010). «Actividades y espacios residenciales de los inmigrantes japoneses en Guangzhu». Diario Geográfico, 65 (10), 1173-1186.

Lyons, Michal; Brown, Alison y Zhigang, Li (2008). "The "third tier" of globalization». City [en línea], 12 (2), 196-206. <http://dx.doi.org/10.1080/13604810802167036>

- (2012). «In the Dragon's Den: African Traders in Guangzhou». Journal of Ethnic and Migration Studies [en línea], 38 (5), 869-888. <https://doi.org/10.10180/1369183X.2012.668030>

- (2013). «The China-Africa Value Chain: Can Africa's Small-Scale Entrepreneurs Engage Successfully in Global Trade?». African Studies Review [en línea], 56 (3), 77-100. <http://dx.doi.org/10.1017/asr.2013.80>

Sheller, Mimi y URry, John (2006). "The new mobilities paradigm». Environment and Planning [en línea], 38 (2), 207-226.

<http://dx.doi.org/10.1068/a37268>

Sмiтh, Michael Peter (2001). Transnational urbanism: Locating globalization. Cambridge, MA: Blackwell.

Soja, Edward (1989). Postmodern Geographies: The Reassertion of Space in Critical Social Theory. Londres: Verso.

Sun, Boyuan (2012). «Situación actual y perspectivas de los barrios internacionales de Beijing». Planificación Urbana de Beijing, 3, 72-76. 
Sun, Yanan (2009). Los barrios coreanos y la ciudad de Qingdao «coreana»: Encuesta de antropología sobre la aculturación de los coreanos en Qingdao. Universidad Central de las Nacionalidades. Tesis doctoral.

URRY, John (2000). Sociology beyond societies: Mobilities for the twenty-first century. Londres: Routledge.

WeI, Li (2006) (ed.). From Urban Enclave to Ethnic Suburb: New Asian Communities in Pacific Rim Countries. Honolulu: University of Hawaii Press.

Wissink, Bart; Kempen, Ronald; Fang, Yiping y Li, Si-ming (2012). «Introduction: Living in Chinese Enclave Cities». Urban Geography [en línea], 33 (2), 161-166. <http://dx.doi.org/10.2747/0272-3638.33.2.161>

Wu, Fulong y Webber, Klaire (2004). «The Rise of "Foreign Gated Communities" in Beijing: Between Economic Globalization and Local Institutions». Cities [en límea], 21 (3), 203-213. <http://dx.doi.org/10.1016/j.cities.2004.03.002>

Xiaoyan, Ma (2011). «La aparición y las características de los barrios de inmigrantes en la construcción urbana mundial: Estudio sobre el Barrio Coreano de Wangjing en Beijing». Prensa de la Universidad de Tecnología de Beijing (versión de ciencias sociales), 11 (6), 8-13.

YE, Hongji (2012). «Transición y reconstrucción de redes sociales en los barrios de inmigrantes». Ciencia Social, 11, 67-75.

Yungang, Liu y Yuwen, Tan (2010). «Dinámica migratoria de Japón bajo la globalización». Geografía Mundial, 19 (3), 62-71.

Yungang, Liu; Yuwen, Tan y Wenting, Zhou (2010). «Actividades y espacios residenciales de los inmigrantes japoneses en Guangzhu». Diario Geográfico, 65 (10), 1173-1186.

ZHANG, Li (2008). «Ethnic congregation in a globalizing city: The case of Guangzhou, China». Cities [en línea], 25 (6), 383-395. <http://dx.doi.org/10.1016/j.cities.2008.09.004>

Zhigang, Li; Desheng, Xue; Feng, Du y Ying, Z. (2009). «La respuesta local de "el espacio social de migrantes transnacionales" bajo la globalización. Ejemplo: el Barrio Africano de Xiaobei». Geografía, 28 (4), 920-932.

Zhigang, Li; Desheng, Xue; Lyons, Michal y Brown, Alison (2008). «Análisis del espacio social del Barrio Africano en la calle Xiaobei de Guangzhou». Journal of Geographical Sciences, 63 (2), 207-218.

Zhigang, Li y Feng, Du (2012a). "Estudio sobre "zonas económicas” de los extranjeros en las grandes ciudades de China: Una confirmación de la "ciudad de chocolate” de Guangzhou». Geografía, 27 (6), 1-6.

- (2012b). «La aparición del nuevo espacio urbano social bajo "la doctrina de comercio transnacional": Una confirmación de la zona económica africana de Guangzhou». Urbanismo, 36 (8), 25-31.

Zhigang, Li; Ma, Laurence y Desheng, Xue (2009). «An African Enclave in China: The Making of a New Transnational Urban Space». Eurasian Geography and Economics [en línea], 50 (6), 699-719. <http://dx.doi.org/10.2747/1539-7216.50.6.699>

Zhou, Min y Lin, Mingang (2004). «El capital étnico y la transformación de los barrios chinos en EE. UU.». Investigación Sociológica, 3, 36-46.

Zhou, Yu (1998). «Beyond Ethnic Enclaves: Location Strategies of Chinese Producer Service Firms in Los Angeles». Economic Geography [en línea], 74 (3), 228-251. <http://dx.doi.org/10.2307/144375> 